\title{
COESÃO TEXTUAL E LEITURA EM AMBIENTE VIRTUAL: A REFERENCIAÇÃO EM POSTE COMENTÁRIOS DE UM BLOG
}

\section{TEXTUAL COHESION AND READING IN VIRTUAL ENVIRONMENT: THE REFERENCE PROCESS IN POSTING AND COMMENTING ON A BLOG}

\author{
Cristina de Souza Vergnano-Junger ${ }^{1}$ \\ Universidade do Estado do Rio de Janeiro (UERJ) \\ Andrea Galvão de Carvalho ${ }^{2}$
}

Universidade Federal do Rio de Janeiro (UFRJ)/Colégio Pedro II

\begin{abstract}
RESUMO: Vivemos na sociedade da informação, envoltos no boom da comunicação digital, contexto no qual a leitura tem-se incrementado, embora com novas feições. O processo leitor, visto como atividade cognitiva e social, envolve diversos conhecimentos, procedimentos e situações, em constante enriquecimento devido às nossas novas experiências (VERGNANOJUNGER, 2010 e 2015). Neste artigo, seguindo a Linguística Textual (KOCH, 2009b e 2009c), propomos a discussão sobre como os aspectos coesivos, em especial o da referenciação (KOCH; ELIAS, 2007 e 2009), se apresentam nos gêneros textuais do par post/comentário em um blog em língua espanhola para professores. Considerando o meio digital e suas especificidades, incluímos na reflexão a questão da coesão hipertextual (MARCUSCHI, 1999.). Procuramos refletir, também, sobre as relações entre as construções coesivas e o processo leitor. Concluímos, com base nos exemplos analisados, que a referenciação intratextual apresenta-se, nesses gêneros, apesar de seu suporte virtual, de forma semelhante àquela observável em outros textos de meio impresso na língua espanhola. No entanto, o caráter interativo dos posts e comentários e a natureza hipertextual da constituição dos textos digitais favorecem enlaces que ultrapassam limites mais restritos e imediatos de cada texto, por meio de coesões inter e hipertextuais. Embora não tenhamos o objetivo de generalizar os processos referenciais nesses gêneros textuais, oferecemos uma descrição de possibilidades e destacamos sua relevância para a construção de sentidos durante o processo leitor. Enfatizamos, em especial, suas implicações quando se trata de compor "textos finais" que extrapolam limites convencionais da noção de texto, aspecto típico da leitura virtual.
\end{abstract}

PALAVRAS-CHAVE: referenciação; leitura; post/comentário; coesão hipertextual

ABSTRACT: We live in the information society, wrapped in the so-called digital communications boom, the context in which reading has increased, though with new features. The reading process, seen as a cognitive and social activity, comprises several skills, procedures, and situations in constant enrichment due to our new experiences (VERGNANO-JUNGER, 2010 e 2015. In this article, following the Textual Linguistics (KOCH, 2009b e 2009c), we propose discussing how cohesive aspects, especially the exophoric and endophoric referencing (KOCH; ELIAS, 2007 e 2009), are presented in textual genres of the pair post and comment on a blog in Spanish for teachers. Considering the digital media and its specific features, we also regard

\footnotetext{
1 Doutora em Letras Neolatinas (Espanhol) pela Universidade Federal do Rio de Janeiro (UFRJ). Professora do Programa de Pós-graduação Stricto Sensu em Letras da Universidade do Estado do Rio de Janeiro (UERJ) crisvj.uerj@gmail.com

${ }^{2}$ Doutora em Linguística pela Universidade Federal do Rio de Janeiro (UFRJ), docente de espanhol do Colégio Pedro II - RJ - andreaprofesp@gmail.com
} 
the issue of hypertextual cohesion (MARCUSCHI, 1999.). Furthermore, we seek to discuss the relations between the cohesive constructions and the reading process. Based on the examples analyzed, we conclude that the intratextual referencing is presented in these genres, despite their virtual support, in a similar way to that observed in other printed texts in Spanish. However, the interactive nature of the posts and comments and hypertextual nature of the digital texts favor linkages that go beyond the more restricted and immediate boundaries of the text, using inter and hypertext cohesions. Even though our goal is not to generalize the referencing processes in these genres, we provide a description of possibilities and highlight its relevance to the construction of meaning in the reading process. We emphasize in particular its implications when it comes to composing "final texts" that go beyond conventional limits of the notion of text, a typical aspect of the virtual reading.

KEYWORDS: referencing; reading comprehension; post/comment; hipertextual cohesion

\section{INTRODUÇÃO: AMBIENTE VIRTUAL, GÊNEROS TEXTUAIS E LEITURA}

A interação mediada por artefatos digitais faz parte ativa de nosso cotidiano. É um fato que observamos facilmente, olhando ao nosso redor. São contatos pessoais e de trabalho, troca de e-mails e postagens em redes sociais, operações bancárias e comerciais, acesso à informação e a diferentes formas de lazer (vídeos e jogos, por exemplo). Isso implica a circulação de variados gêneros textuais e a criação ou reelaboração de atitudes, procedimentos de acesso, comunicação e, claro, leitura.

Mas nem todas as pessoas manifestam-se favoravelmente ao uso dos recursos informáticos em todas essas situações. Embora não nos baseemos em estudos prévios específicos para afirmá-lo, nossa experiência, tanto como usuárias como quanto docentes, nos vem colocando em contato com depoimentos a respeito. Trata-se de estudantes que passam grande parte do tempo conectados, teclando e lendo mensagens em seus celulares, mas se queixam de dificuldades para ler textos de estudos na tela, ou para usar satisfatoriamente os recursos de ambientes virtuais de aprendizagem (AVA). São professores que declaram não entender muito bem como funcionam certas redes sociais ou programas informáticos e que preferem fazer apenas o básico no computador: troca de e-mails, edição de textos e alguma leitura. São jogadores de videogames que, apesar de sua habilidade com a máquina e os softwares, perdem-se em navegações de jornais e portais de fontes bibliográficas. Esses são alguns exemplos entre muitos que se poderiam encontrar. O que ocorre, então?

Prensky (2001) defende que a diferença é geracional. Basicamente, existiriam dois grupos de usuários. Primeiro, haveria os nativos digitais, nascidos e criados na sociedade da informação, para quem o uso das tecnologias da informação e comunicação (TICs) faz parte de sua forma de ver e agir no mundo. Em segundo, estaríamos nós, nascidos anteriormente ao boom informático, os imigrantes digitais cujo pensamento e atividades seriam analógicos, o que justificaria nossas dificuldades na relação com esse novo paradigma digital.

Mesmo admitindo que isso de fato ocorra, nossos estudos têm apontado para outra possibilidade (VERGNANO-JUNGER, 2012). Não seria o fator geracional (ao menos, não apenas ele) o que garantiria ou limitaria, necessariamente, o desempenho satisfatório na leitura/escrita mediada por computadores. Entrariam em jogo, entre outros aspectos, os conhecimentos relacionados aos gêneros e a procedimentos específicos. Sendo assim, defendemos que cada indivíduo, considerando seus objetivos, necessidades e conhecimentos prévios, terá atitudes, ações e desempenhos diferenciados na interação envolvendo a palavra escrita mediada pelas TICs. Tal fato dependeria, portanto, das circunstâncias de uso e bagagens de cada um. Tudo isso está, desse modo, relacionado ao (nível de) letramento das pessoas, entendido tanto como o fazer coisas por meio da escrita (CERUTTI-RIZZATTI, 2012), quanto ao estado desses indivíduos que realizam tais práticas sociais mediadas pela leitura e a escrita 
(SOARES, 2002). Esse continuum de ações e capacidades pode evoluir ao longo da vida (GASQUE, 2010) em função das experiências, do contato com novos gêneros, demandas e formas de solucionar questões que a própria vivência social num mundo letrado apresenta.

Os materiais que circulam em meio virtual (e destacamos, especialmente, a internet por seu uso cada vez mais intenso e diversificado), embora possam ser de diversas naturezas, reúnem um grande contingente de textos verbais. Isso significa que a interação mediada pelas TICs envolve práticas letradas que demandam muita leitura. Quando pensamos, portanto, na questão estratégica, referimo-nos às tomadas de decisão desse leitor/autor em função do desenho que a tecnologia permite/favorece para os textos de ambientes digitais. Aqueles, que são eminentemente desse/para esse suporte, constroem-se de forma hipertextual e, com frequência, multimodal. Isso implica uma constituição não hierárquica, fragmentada, sem um centro específico, efêmera, virtual e que utiliza diferentes linguagens concomitantemente (VERGNANOJUNGER, 2015). Tais características demandam do sujeito um tipo de monitoramento cuidadoso do processo leitor (PERFETTI; LANDI; OAKHILL, 2013), que envolve seleção, avaliação, controle e inferências, para garantir o alcance de seus objetivos e a construção de uma compreensão efetiva.

Faz parte desse cenário, também, o (re)conhecimento dos gêneros textuais, tanto no que se refere a eles enquanto modelos cognitivos, como à sua relação com as práticas sociais, a sociedade e o tempo em que estão inseridos (VERGNANO-JUNGER, 2015). As demandas sociais e comunicativas levam aos ajustes/mudanças ou criação de gêneros (MARCUSCHI, 2008), cujos padrões e funções devem ser conhecidos pelos seus usuários para uma interação adequada. Isso, em nossa avaliação, pode explicar por que usuários proficientes de TICs apresentam dificuldades em certas circunstâncias e não em outras. Ou seja, concluímos que o fato de participar assiduamente de uma rede social, postando e lendo comentários, por exemplo, não necessariamente garante uma navegação sem problemas num portal de periódicos acadêmicos.

A leitura, atividade essencial quando se pensa na interação mediada por computadores ${ }^{3}$, envolve, no entanto, mais do que os aspectos procedimentais (como, monitoramento, controle e inferências), o (re)conhecimento de gêneros, ou o fato de encará-la como uma prática social, com tudo o que isso implica. Ela pressupõe a capacidade de o leitor ativar uma ampla bagagem de conhecimentos, relacionando-os entre si e com todo o material lido (VERGNANO-JUNGER, 2010).

Seguindo, então, uma orientação da Linguística Textual (KOCH, 2009b; 2009c), destacamos o papel da coesão textual, em especial da referenciação, no processo leitor. No entanto, como propomos lançar nosso olhar, especificamente, sobre a referenciação em textos digitais com construção hipertextual, trazemos um alerta de Marcuschi (1999) sobre o tema. Segundo o autor, a natureza hipertextual dos textos digitais favorece sua não centralidade e fragmentação, como já comentamos, e a composição de "textos finais" a partir da conjugação de vários materiais distintos, que não ocupam necessariamente o mesmo espaço virtual. Isso implica uma falta de ordem estrutural predeterminada e um conjunto de possibilidades, que variará em função das escolhas de cada navegador a partir dos links que lhe forem oferecidos. As ações tomadas nessas circunstâncias serão baseadas em "referenciações não contínuas nem progressivas" (MARCUSCHI, 1999, 7). Portanto, concluímos que, para que se construa coerência a partir da navegação e da leitura de diferentes textos dispersos na internet, que passam a ser conjugados num "texto final" por determinado leitor, é preciso pensar numa coesão hipertextual, que tem um caráter intertextual por se estabelecer entre os vários textos colocados em diálogo por meio da navegação. Isso é o que propomos na discussão nos itens seguintes, ao lado das

\footnotetext{
${ }^{3}$ Levamos em consideração, como já afirmamos, que muito do material que circula na internet envolve linguagem verbal. Além do mais, nem sempre há oportunidade de interagir por meio da fala, predominando, assim, os textos escritos. Portanto, a leitura constitui, ainda, a forma principal de acessar e reconstruir os sentidos que circularão durante as interações. Em muitas ocasiões, é o pré-requisito para que as ações ocorram, como no caso das instruções para se inscrever num determinado site, por exemplo.
} 
considerações sobre o processo coesivo interno em cada texto.

O presente artigo, partindo desta proposta, está estruturado em três blocos. No primeiro, voltamo-nos para considerações teóricas sobre coesão e referenciação. A seguir, selecionamos um post de um blog e alguns de seus comentários para discutir as relações coesivas que se podem estabelecer. E, na conclusão, refletimos sobre como esses aspectos da Linguística Textual podem contribuir para o processo de construção de sentidos durante a leitura.

\section{$1 \mathrm{Um}$ pouco de teoria: coesão e referenciação}

Para começar a reflexão sobre o tema deste tópico e lançarmos, como proposto, um olhar sobre a referenciação numa coesão hipertextual, reportamo-nos, primeiro, ao conceito de texto. Com base em uma concepção interacional (dialógica) da língua, concebemos o texto como lugar de interação e seus interlocutores como sujeitos ativos que - dialogicamente - nele se constroem e são construídos (KOCH, 2009b). Assumimos "texto", portanto, como uma unidade de sentido, um produto delimitado, mas que é proveniente de um processo comunicativo.

A partir da concepção de texto da Linguística Textual, é relevante para este estudo destacar que não só os textos em ambiente virtual podem ter uma construção hipertextual. Todo texto possibilita construções variadas de sentido, ainda que não permita toda e qualquer uma. As múltiplas possibilidades de leitura de um texto estão relacionadas aos objetivos de leitura e conhecimentos prévios de cada leitor. Ao ler, estabelecemos relações com as informações dadas pelo texto e nossos conhecimentos, em um constante movimento em várias direções, com acesso constante a diversas fontes de informação, tanto textuais como extratextuais. Como pontua Koch (2009b, 63), "verifica-se que a compreensão não se dá de maneira linear e sequencial, como se pensava antigamente, o que vem a constituir um argumento a mais para afirmar que todo texto é um hipertexto". Isso nos permite relativizar o conceito de texto como um produto fechado, com limites firmemente demarcados.

Ainda tratando dessa questão e remetendo à posição de Marcuschi (1999) sobre a coesão hipertextual, enfatizamos que, numa situação de produção/recepção de textos em ambiente digital, os critérios de textualidade precisam ser flexibilizados, ou, ao menos, ponderados criticamente. Isso porque a hipertextualidade constitutiva dos textos virtuais abre inúmeras possibilidades de composição final do material acessado (VERGNANO-JUNGER, 2010; 2015). O autor digital compõe textos nos quais oferece possibilidades de caminhos de leitura/navegação, segundo seus interesses, objetivos ou necessidades. Podem ser acréscimos de conteúdo, explicações, abertura para espaços de comentários, derivações do tema, conexão com assuntos relacionados, materiais publicitários que o ajudam a manter sua página etc. O leitor, por sua vez, não está obrigado a seguir nenhum deles. Pode optar pelo que lhe interessa; acessar links e imediatamente abandoná-los; abrir links sucessivos, não retornando ao início; traçar um "plano" de leitura sistemático, controlando os acessos; estabelecer ou não relação entre os diferentes materiais visitados... No final, terá atualizado um "texto" cujos limites vão muito além de uma unidade de sentido com um princípio, meio e fim claramente circunscritos. Mais ainda, vários leitores, partindo de um mesmo texto inicial, poderão escolher trajetórias tão distintas que gerem produtos variados dos diferentes processos que cada um realizou ao ler. Concluímos, portanto, que, além da coesão interna ao cotexto (intratextual), é necessário considerar uma coesão intertextual/ hipertextual.

Neste estudo, como já antecipamos, nosso foco está voltado para a análise da coesão, mais especificamente a da coesão referencial, incluída a de contexto hipertextual. Assim, definido o que assumimos como texto, inclusive considerando o meio virtual e a relativização de limites, apresentamos uma revisão de alguns conceitos-chave para aplicá-los e observá-los a continuação.

A referenciação diz respeito às distintas formas de introdução, no texto, de novas entidades ou referentes. Ou seja, o processo de referenciação diz respeito à maneira como construímos e reconstruímos os objetos de discurso (ou referentes) no interior do discurso, 
segundo nossa percepção de mundo, nossas crenças, atitudes e objetivos comunicativos (KOCH; ELIAS, 2009). É, portanto, uma atividade discursiva, na qual, o sujeito, no decorrer da interação verbal, escolhe as formas de referenciação mais adequadas em função da sua interação e do seu dizer (KOCH; ELIAS, 2007).

Os processos referenciais, dessa forma, estão em constante construção, uma vez que não preexistem ao discurso; mas são, na verdade, ativados e reativados discursivamente. As formas de introdução de novos referentes e a retomada de elementos já apresentados originam a progressão referencial.

A referenciação, assim como a progressão referencial, consiste na construção e reconstrução de objetos de discurso. Ou seja, os referentes de que falamos não espelham diretamente o mundo real, não são simples rótulos para designar o mundo. Eles são construídos e reconstruídos no interior do próprio discurso, de acordo com a nossa percepção do mundo (...). (KOCH; ELIAS, 2007, p. 123).

Desse modo, a construção e reconstrução de referentes não depende exclusivamente do saber construído linguisticamente pelo texto e das inferências possibilitadas pelos elementos textuais. A referenciação demanda também "os saberes, opiniões e juízos mobilizados no momento da interação autor-texto-leitor" (KOCH; ELIAS, 2007, p.125).

A coesão referencial, foco principal do nosso estudo, se apresenta por meio de itens da língua que fazem referência a outros elementos presentes no texto, ou que possam ser inferidos a partir do universo textual (KOCH, 2009a). Esses itens não são interpretados semanticamente por seu sentido próprio, mas fazem referência a algum elemento necessário à sua interpretação. Esse tipo de coesão pode ser realizado por meio de diferentes recursos. Alguns deles são de ordem gramatical, como pronomes, verbos, advérbios e numerais. Outros são de ordem lexical, com a reiteração de itens lexicais: sinônimos, hiperônimos, hipônimos, expressões nominais definidas e nomes genéricos (como "gente", "pessoa", "coisa", "negócio", "lugar", etc.). A elipse de entidades já apresentadas no texto também é um mecanismo de coesão referencial. Ademais, a referenciação pode ser realizada tanto por meio de processos anafóricos, quanto catafóricos. No primeiro caso, ocorre quando há um resgate de termos anteriormente explicitados no texto. No segundo, quando a referência é feita sobre o que ainda será mencionado.

Como já destacamos, Marcuschi (1999) nos lembra que os textos em ambientes virtuais, por sua construção hipertextual, remetem a um tipo de coesão que se tece entre textos, até alcançarmos o produto final de nossa leitura. Isso se dá pela navegação de um texto a outro por meio de links, o que leva o leitor a compor um conjunto, um todo, segundo seus interesses, objetivos, necessidades e situação de leitura. No hipertexto, portanto, os links têm um importante papel na construção do conhecimento ao desempenharem funções dêiticas ${ }^{4}$ e coesivas no processo de construção hipertextual. Os hiperlinks dêiticos têm o objetivo de sugerir caminhos de leitura no espaço digital. Têm um caráter catafórico, porque remetem o leitor para fora do hipertexto que está sendo lido naquele momento na tela do computador e permitem acessos virtuais a outros, de alguma forma correlacionados à temática desenvolvida no texto principal (KOCH, 2009b).

Ao atuarem como operadores de coesão, os biperlinks estabelecem elos coesivos, complementando informações, fornecendo novos dados e proporcionando uma leitura fluida (KOCH, 2009b). Desta maneira, "outra função importante dos hiperlinks, além de entrelaçar discursos no espaço cibernético, é amarrar as informações de modo a permitir que os leitores extraiam delas um conhecimento real e conclusões relativamente seguras (...)" (KOCH, 2009b: 65). Por isso, ainda segundo Koch (2009b), os links não devem estar presentes no hipertexto de maneira excessiva, de modo que gerem interrupções massivas e provoquem a dispersão do leitor. Tampouco devem colocar-se de modo aleatório, sem que contribuam para e/ou auxiliem o

\footnotetext{
4 "São denominadas dêitico as unidades linguísticas cujo valor referencial depende do entorno espaço-temporal no qual ocorrem” (MAINGUENEAU, 2008, p.34).
} 
processo leitor de construção do sentido hipertextual.

É possível argumentar que há outra forma de promover coesão referencial entre textos de ambiente virtual sem, necessariamente, contar com os links. Destacamos, neste caso, a relação existente entre posts e comentários. Como pontua Lima (2015), embora possa haver posts sem qualquer comentário, os comentários necessitam um texto que os motive. Esses podem ser tanto os posts como outros comentários. Por isso, dada a relação que possuem entre si, é factível admitir que possa ser construído um laço coesivo referencial, de caráter anafórico, entre eles, os quais podem marcar-se tanto por itens lexicais, quanto por itens gramaticais.

Quando pensamos na leitura, a percepção, o reconhecimento e a articulação crítica das relações coesivas entre os elementos da língua podem contribuir para negociar significados e construir sentidos. Entre outras funções, a atenção à coesão referencial permite a retomada/antecipação de informações e elementos do discurso, traçando relações, diminuindo dúvidas e ambiguidades, preenchendo lacunas, facilitando inferências. Tais ações podem resultar relevantes no decorrer da leitura, no sentido de permitir ao leitor o alcance mais satisfatório de seus objetivos. A não observância dos aspectos coesivos, por sua vez, pode levar a dificuldades de compreensão e do estabelecimento de coerência. No que se refere à especificidade dos materiais de ambiente digital, podem, ainda, auxiliar a unir textos dispersos e a construir uma coerência final mais consistente. Tal característica pode vir a contribuir para minimizar os efeitos da dispersão própria da não centralidade e não hierarquização dos textos virtuais.

\section{A coesão e a referenciação hipertextual: discussão numa amostra de post/comentário}

A partir da consideração dos conceitos de coesão e referenciação expostos anteriormente e do foco na compreensão leitora de textos do ambiente virtual, descrevemos e analisamos o processo de coesão e referenciação hipertextual em um post e seus respectivos comentários. Nosso questionamento volta-se para como se manifesta a coesão - seja a intratextual, ou a hipertextual - nesses gêneros. Em segunda instância, perguntamo-nos sobre que relações podem ser estabelecidas entre essas características constitutivas e o processo leitor de posts e comentários.

Assumimos ambos (post e comentário) como gêneros textuais próprios do ambiente digital; diferentes, embora relacionados, seguindo a proposta de Lima (2015) ${ }^{5}$. No caso do post, sua função comunicativa básica é a de compartilhar experiências, informações e materiais com os sujeitos leitores (na amostra que escolhemos, professores de espanhol como língua estrangeira). Sua estrutura formal, neste caso em particular (do blog jramonele.com), apresenta: (a) uma tipologia expositiva; (b) linguagem cuidada em língua espanhola, com o uso da primeira pessoa do plural, incluindo o receptor da mensagem; (c) um título para cada post, (d) a possibilidade de itens e subitens, dividindo o texto em partes; (e) presença de imagens e links. Seus conteúdos são variados, mas estão diretamente vinculados ao contexto social e comunicativo no qual se gesta o blog. Ou seja, o da interação com/entre docentes de espanhol como língua estrangeira (ELE), a fim de promover o compartilhamento de recursos e técnicas e favorecer o crescimento profissional dos leitores participantes. Posts são gêneros autônomos, no sentido de que, embora se espere a manifestação dos leitores, sua existência não depende dela.

Os comentários, por sua própria função comunicativa, são responsivos ao post ou a outros comentários. Isso significa que, ao propor reflexões, manifestação de opinião, perguntas ou respostas, seus autores o fazem motivados por textos prévios presentes no espaço do blog. Como propõe Lima $(2015,171)$, isso marca "sua co-dependência enquanto gênero" com as postagens de outros participantes da interação. Em termos de forma, os comentários costumam ser mais breves; informais, ainda que, devido ao perfil dos leitores, haja a tendência a ser usada

\footnotetext{
5 A autora, em seu texto, trabalha com posts e comentários da rede social Facebook. Embora estejamos analisando esses gêneros em um blog, ou seja, em outro suporte, consideramos que as conclusões sobre o par post/comentário no suporte rede social mantêm correlações suficientes com nosso corpus atual para levarmos em consideração as conclusões teóricas apresentadas no referido estudo.
}

Revista do GELNE, Natal/RN, Vol. 21 - Número 1: p. 89-103. 2019 
uma modalidade cuidada da língua; admitem o uso de emoticons, links ou recursos não verbais. Seu conteúdo, dada a sua natureza codependente de outros textos, segue o caminho do post ou de outro comentário que responde, versando, no blog escolhido em particular, em torno a temas sobre o ensino de ELE.

Para selecionar o post e seus comentários, optamos, como já foi antecipado na explicação prévia sobre a caracterização dos gêneros, por pesquisar blog de professores de espanhol. Fizemos isso em virtude de nossa experiência como docentes e buscamos fontes cujo objetivo fosse o diálogo com outros professores. Entendemos que esse suporte virtual favorece o intercâmbio entre tais profissionais, fomentando o uso interativo da linguagem e a necessária prática leitora. Isso nos oferece um material variado para discutir a coesão, não somente no âmbito do cotexto, como na intertextualidade favorecida pela sua construção hipertextual.

\subsection{0 post}

O blog selecionado, jramonele.com, existe desde 2000 e é de autoria de um professor nativo de espanhol como língua estrangeira (ELE) residente na Espanha. Seus objetivos são (a) discutir questões de ensino aprendizagem de espanhol como segunda língua e (b) compartilhar com os leitores do blog atividades elaboradas tanto por seu autor, como por outros docentes. A língua utilizada é o espanhol.

No site, links permitem o acesso a informações sobre o blogueiro, seu trabalho e publicações. Também aparecem contagem de visitantes; indicação de seguidores; espaço para entrar em contato com o autor, enviando mensagens; algumas publicidades e links para posts antigos, verticalmente, à direita. Dois gêneros, contudo, destacam-se entre os presentes no suporte, inclusive por ocuparem o espaço central da página inicial: os posts do autor e os comentários (de leitores, mas também do autor). Estes últimos nem sempre existem e, quando estão presentes, podem ser visualizados ao final da postagem do blogueiro.

Logo após o post, também se indicam alguns links relacionados ao tema desenvolvido e etiquetas que levam a outros posts selecionados e organizados de alguma maneira afins ao lido (por exemplo, pelo nível de ensino da língua, pela temática, pela proposta didática, por conteúdo de estudo etc). Está presente, por fim, o número de comentários que foram feitos para o post imediatamente anterior.

O post escolhido para esta análise foi "Los gremios: las oraciones relativas en las calles de Málaga", publicado em 7 de abril de 2015. Nele, se oferece aos leitores uma atividade baseada, inicialmente, em um aspecto cultural: descobrir a origem dos nomes de algumas ruas da cidade de Málaga, na Espanha. No entanto, se desdobra, a seguir, no estudo gramatical das orações relativas.

O texto divide-se em uma introdução, na qual o autor conta sobre as suas inspirações para a criação do exercício, e outras quatro partes, nas quais a atividade é apresentada e explicada. Quanto à referenciação interna ao texto da postagem, podemos observar diferentes tipos de enlaces que se constroem tanto por meio de pronomes, quanto pela seleção lexical.

Logo no primeiro parágrafo, o autor recupera o nome do livro que comprou em Londres e foi o motivador inicial da atividade proposta no seu blog. Emprega para tal o artigo "el" ("o" em português) e o pronome relativo "que", numa referência anafórica:

\section{Hace un par de años me compré en una tienda de Covent Garden un librito titulado Why do shepherds need a bush? en el que secuenta el origen de los nombres de las estaciones de metro de la capital londinense.}

Figura 1: Primeiro exemplo de coesão referencial anafórica com pronome relativo

No segundo parágrafo, a fórmula se repete, com a anáfora por meio do pronome relativo: 


\section{sobre los barrios cofrades, en (1os que}

Figura 2: Segundo exemplo de coesão referencial anafórica com pronome relativo

No entanto, podemos observar no mesmo parágrafo (Figura 3) outra construção coesiva referencial, realizada não mais por pronome, mas por meio de uma relação hiperonímica entre "ciudad" ("cidade", em português) e "Málaga" e hiponímica entre "capital" e "ciudad". Parecenos relevante destacar, contudo, que essa recuperação referencial não é imediata ou direta, demandando certo grau de inferência. No segundo parágrafo não se faz referência à Málaga. De fato, a informação mais imediata que possuíamos sobre uma cidade era aquela relacionada à Londres, presente ao final do parágrafo anterior (ver Figura 1), por meio do sintagma "capital londinense". Portanto, para construir coerência, o leitor precisa utilizar conhecimentos de mundo, como, por exemplo, identificar a origem malaguenha do jornal citado (Diario Sur), ou a relação entre Málaga e as cofradías, o que pode ser complementado com a noção de que Málaga é uma capital de província espanhola. Esse conhecimento pode facilitar o enlace coesivo entre "ciudad", presente no parágrafo e seu nome no título: "Málaga" (Figuras 3 e 4).

A remissão de "capital" a "ciudad", mesmo que não se saiba exatamente de qual lugar se trata, é mais fácil e direta, já que se encontram no mesmo parágrafo. Além disso, o uso do artigo definido reforça a noção de que essa capital já era conhecida do leitor, ou seja, já lhe havia sido apresentada no texto. Em ambos os casos, observamos referências anafóricas por meio de itens lexicais.



Figura 4: Referente da anáfora por hiperônimo do segundo parágrafo

No decorrer da planificação da aula apresentada no post, encontramos uma referência exofórica. Isso ocorre quando o blogueiro refere-se aos alunos, que não foram citados anteriormente, mas os quais reconhecemos como os sujeitos a quem a atividade será aplicada, devido ao contexto de sala de aula e à proposta descrita. Trata-se de uma referência de ordem gramatical, já que a recuperação do referente se faz por meio de uma pessoa verbal e do uso enfático do pronome "se", que remete reflexivamente aos próprios alunos que encontrariam a palavra escrita no quadro ao chegar à sala: “... se la encuentren al llegar...” (Figura 5).

\section{Gremio \\ Poder $/$ s partir del significado de la palabra gremio. Podemos, a modo de calentamiento, escrib @a la pizarra y que se a ncuentrenal llegar; jugar al ahorcado con la palabra; acompanar la palabra en la pizarra con varias tarjetas con posibles definiciones de las que solo una es verdadera; o cualquier otra idea que se 0 . 0 curra para contextualizar}

Figura 5: Exemplos de referência exofórica e endofórica 
Ainda no fragmento “(...) que se la encuentren al llegar (...)" (Figura 5), temos o pronome "la" ("a" em português) retomando "gremio", por referência hiperonímica, já que se associa à "palavra", a qual será escrita no quadro (neste caso, "gremio"). Também, ao final do fragmento, em "(...) que se os ocurra para contextualizar", estamos diante de outra remissão feita a um elemento da situação comunicativa (referência exofórica e dêitica): os interlocutores professores. O pronome oblíquo "os" (segunda pessoa do plural, utilizada para tratamento informal dirigido aos interlocutores, na Espanha) refere-se aos leitores do post.

No segundo parágrafo do subitem "Calles de Málaga - o segundo do post - (Figura 6), estamos diante de uma elipse de sujeito tanto em "dividiremos" como em "trabajen" e "planteen". O verbo "dividiremos" conjugado na primeira pessoa do plural remete ao interlocutor do post, que seria um docente, e inclui o seu autor. Tais elipses são frequentes em espanhol, língua cuja tendência é omitir os pronomes pessoais com função de sujeito sempre que este esteja claro pelo contexto, ou pelas marcas de desinência verbal.

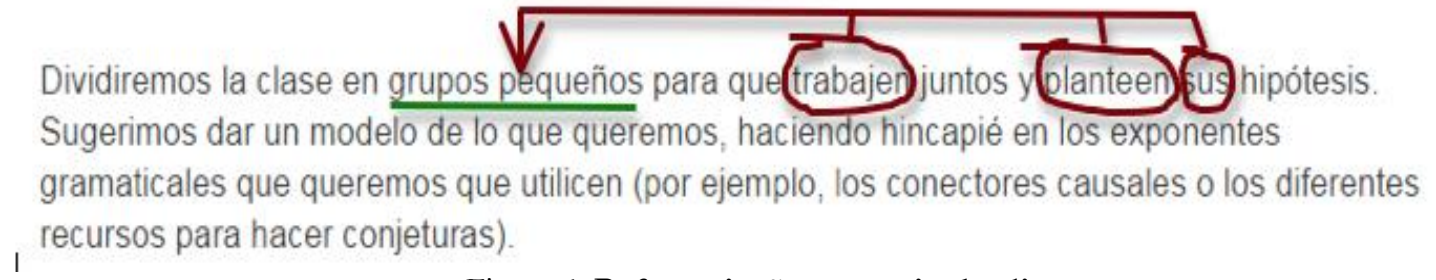

Figura 6: Referenciação por meio de elipses

Já em "trabajen" e "planteen" (Figura 6) os verbos fazem referência aos discentes a quem a atividade seria aplicada, mais especificamente aos "grupos pequeños" [desses alunos]. Outra referência a esses grupos de estudantes está presente em "sus hipótesis". O pronome "sus" refere-se, uma vez mais, aos alunos que são parte da situação comunicativa. Faz isso, no entanto, por meio da relação lexical metonímica da parte (grupo pequeno desses alunos) pelo todo (alunos, em elipse). Outro detalhe nessa retomada é que ela é realizada por meio não diretamente dos alunos, mas de algo que lhes "pertence", ou seja, das hipóteses que propõem, usando o autor, para tal, o possessivo "sus" ("suas" em português).

Em “(...) y que lo expliquen (...)" (Figura 7), o pronome "lo" remete o leitor não a uma palavra específica, mas sim ao ato de explicar a vinculação das ruas com algum grêmio ou profissão. No caso dos aprendizes brasileiros de espanhol, esse tipo de referenciação é de especial dificuldade, pois utiliza um pronome pessoal neutro, sem equivalência no português, língua na qual usamos a forma masculina tanto para as referências a nomes quanto para expressões ou ideias.

\section{(m) Refino, (n) Vendeja y (ñ) Zapateros. Después, preguhtamos cuáles de las calles creen que tienen vinculación con algún gremio o profesión y quđరoxpliquen. Hemos incluido algún que otro distractor, claro. \\ Figura 7: Referenciação a ideias, utilizando pronome neutro}

No que se refere à referenciação hipertextual, temos que lançar nosso olhar não apenas para o interior do texto, o cotexto, mas para seu exterior. Ao fazê-lo, devemos observar os links oferecidos pelo autor do post, os caminhos onde nos levam e a coerência que podemos estabelecer a partir dessa coesão construída em colaboração por autor e leitores.

$\mathrm{Na}$ introdução, o blogueiro esclarece, como já pontuamos, que elaborou a atividade com base no livro "Why Do Shepherds Need a Bush?”, comprado há alguns anos, em revistas temáticas publicadas pelo jornal "Diario Sur" e na obra de referência "Enciclopedia del callejero malagueño". Ao citar o livro em inglês e a enciclopédia, o autor oferece dois linkes ao leitor que o direcionam para a aquisição das obras (dois sites de livrarias virtuais). Os links em nada auxiliam na 
leitura do post. Entretanto, podem conectar-se coerentemente com ele para o docente leitor que pensa utilizar a atividade, interessado em aumentar o seu conhecimento sobre as ruas de Málaga. Também pode favorecer o conhecimento de uma das obras que deu origem ao post e que conta a origem dos nomes das estações de metrô de Londres. Estaríamos, então, diante de biperlinkes com uma função dêitica e catafórica, pois levam o leitor para fora do texto inicial, apontando outro lugar em que se encontram os referentes "livro em inglês" e "enciclopédia". A coesão se estabelece entre os nomes das obras e os dados comerciais sobre elas disponibilizados nas novas páginas acessadas, podendo ser considerada uma referência construída a partir de itens lexicais, por repetição dos títulos das publicações.

Ainda quanto ao seu papel coesivo, esses links fornecem dados novos que podem ampliar o escopo de informações do leitor. Mas, como pontuado anteriormente, não auxiliam especificamente na construção do sentido do post. Ou seja, são recursos que se afastam da proposta central da postagem e podem, por isso, favorecer a fragmentação da leitura e a dispersão da atenção ao tema em pauta. No caso da enciclopédia, inclusive, há o agravante de que a obra já não pode ser comprada, pois está esgotada. Estamos, assim, diante de um link dispensável na construção do hipertexto, cujo papel coesivo e referencial se perdeu em termos de conteúdo e função. Esse fato pode ocorrer com frequência em textos da internet, dada sua volatilidade. Portanto, é mais um aspecto que merece a consideração do leitor ao atualizar seu hipertexto "final" por meio dos diferentes acessos, monitorar e controlar seus trajetos e construir sentidos, enlaçando os vários materiais consultados.

Há outros dois links presentes na introdução, um dos quais direciona o leitor para a página inicial do Diario Sur (ver Figura 3). É, portanto, dêitico e referencial catafórico, de natureza lexical. No entanto, essa coesão não se dá no sentido do conteúdo do blog, mas sim na recuperação do jornal em si. Isso pode resultar um fator que, ao invés de contribuir para a coesão e construção de coerência durante a leitura, disperse e prejudique o processo leitor devido à variedade e excesso de informação nova e alheia ao conteúdo do post.

Ao acessar a página do jornal, o leitor encontra um contexto que não apresenta nenhuma notícia relevante para o tema discutido no post. Ademais, seu conteúdo muda constantemente em função de suas edições e dias de acesso e oferece inúmeros outros textos para serem lidos. Isso pode ocasionar a mudança no foco de leitura, ou mesmo levar o sujeito a perder-se do caminho previamente estabelecido, sem retomar a leitura inicial do post.

A alteração da trajetória leitora é algo previsto numa construção hipertextual. Em geral, atende aos objetivos, interesses e necessidades do leitor. Não se pode, contudo, considerar que é garantida a manutenção da coesão entre o texto de partida (com seu link) e os textos da nova fonte externa acessada. Ela poderá limitar-se, então, apenas à referência ao nome do novo suporte, presente no blog e no jornal. A coerência proveniente desse processo coesivo se estabelecerá, muito provavelmente, no sentido de conhecer melhor o veículo midiático que foi citado pelo blogueiro.

O outro dos dois links - "barrios cofrades" - (ver Figura 3) leva o leitor para uma página que divulga a venda de uma revista oferecida pelo periódico Diario Sur. Segundo o autor, esta foi um dos estímulos para a elaboração da atividade proposta. Mas o acesso ao link não fornece os conteúdos da publicação, que ajudariam o leitor a entender a motivação do blogueiro. Ao contrário, apenas oferece sua ementa, dados sobre seu formato, datas de entrega, títulos, imagens de capa, preços e contatos para compra. Portanto, consideramos tratar-se, como nos casos anteriores, de coesões dêiticas e catafóricas, de caráter lexical, que não contribuem (ao menos diretamente) para a construção de sentidos do post.

$\mathrm{Na}$ terceira etapa de estruturação da atividade (um dos subitens do post em estudo), o blogueiro oferece 15 explicações sobre a origem de nomes de ruas de Málaga para que os discentes estabeleçam uma relação entre o exposto e o trabalhado anteriormente em aula (Figura 8). 




Figura 8: Fragmento de proposta de atividade com links coesivos referenciais hipertextuais

Das 15 explicações, (a) duas não têm nenhum link, (b) quatro apresentam links que remetem às páginas da Wikipedia e mostram informações gerais sobre a rua em questão, (c) oito links direcionam o leitor ao site "Callejero de Málaga" que apresenta a posição das ruas no mapa da cidade, (d) um link, presente na palavra "refinado", envia o leitor à Wikipedia para explicar como se dá o refino de óleos. Assim, temos 12 links que encaminham o leitor para fora do site e adicionam informações úteis para aumentar o conhecimento do discente sobre o tema cultural do post. a origem do nome das ruas de Málaga. A própria construção de grande parte das proposições da atividade (Figura 8) é dêitica (observar o uso dos pronomes demonstrativos) e sugere a remissão ao item destacado - a rua em pauta na descrição, a ser descoberta pelo aluno.

O post selecionado apresenta, ao final do texto, uma série de links agrupados sob a denominação de "Etiquetas" e que remetem o leitor a outros posts publicados anteriormente no blog. Em "Los gremios: las oraciones relativas en las calles de Málaga" foram publicadas 8 etiquetas nomeadas: $\mathrm{B} 1, \mathrm{~B} 2^{6}$, cultura, ele, gramática, ideas, léxico e recursos. As etiquetas permitem que o leitor acesse posts relacionados de alguma maneira ao tema do texto que está sendo lido, tendo como base a categoria indicada na etiqueta e que lhes seria comum. São, portanto, uma forma de ampliar o conhecimento do leitor a respeito das informações compartilhadas no post principal. Para ilustrarmos a coesão hipertextual nos comentários, aproveitamos essa estrutura coesiva oferecida pelas etiquetas para selecionar um material adicional de análise, apresentado no tópico seguinte.

\subsection{Os comentários}

O post que dá a partida à interlocução aqui exemplificada, como comentamos, data de 07 de abril de 2015. Teve, entre os dias 08 e 12 de abril desse ano, cinco comentários. Três deles foram postados por leitores, dois pelo blogueiro em resposta/comentário às contribuições dos colegas.

Uma vez que se trata de um gênero necessariamente responsivo, espera-se que, de forma direta ou indireta, seja estabelecida uma coesão intertextual. Destacamos que nos comentários ao post selecionado não temos exemplos de coesão hipertextual por meio de links para textos externos ao blog, ou mesmo para outros posts do mesmo autor. Observamos, apenas, alguns exemplos de coesão intertextual entre os diferentes textos dos dois gêneros aqui analisados. Uma hipótese a respeito pode ser o fato de que a natureza e proposta do blog levam os docentes leitores a buscarem materiais mais do que se inclinar a oferecê-los. Dessa forma, em lugar de participar de uma troca de endereços web onde se encontrariam novos recursos relacionados ao tema em pauta, os comentaristas tendem a comentar, elogiar, ou agradecer a iniciativa do autor.

\footnotetext{
${ }^{6}$ A1, A2, B1, B2, C1 e C2 são classificações de níveis de proficiência em língua estrangeira, segundo o estabelecido pelo documento de referência para o aprendizado de línguas na Comunidade Europeia - Marco Común Europeo, em espanhol. A1 é o nível mais elementar, enquanto C2, o mais avançado. As etiquetas B1 e B2, portanto, nos fazem supor que a atividade proposta é de nível intermediário e que há outras no blog que seguem a mesma classificação. Disponível em: <http://cvc.cervantes.es/ensenanza/biblioteca_ele/marco/>.
} 
Ou seja, mantêm-se como leitores mais passivos, não como coautores que promovem a interação entre todos e o enriquecimento do texto pela oferta de novos caminhos de leitura.

Vejamos, então, como se constrói a coesão referencial nos comentários. Temos, na primeira oração do comentário 1 (Figura 9), o sintagma "la idea" ("a ideia", em português), que faz referência à atividade proposta, a todo o seu conjunto exposto no post. Nesse caso, a referenciação é realizada pela utilização de um nome genérico (ideia) e estabelece um vínculo entre o comentário e a postagem (intertextual).

Em termos do cotexto, ainda no comentário 1 (Figura 9), temos a dêixis ao sujeito enunciador apresentada de duas formas, ambas de ordem gramatical. O primeiro caso é realizado por meio do verbo em primeira pessoa do plural, o que não só inclui a professora que comenta (Marisa), como todos os moradores de Madrid, entre os quais se encontra. O segundo caso refere-se ao uso do pronome obliquo "me" em "me será fácil aplicarla", indicando que ela terá facilidade de aplicar a atividade com seus alunos.

\section{드 Marisa Coronado dijo... \\ Me gusta mucho la idea. Con la cantidad de calles con nombres de gremios que tenemos en el casco antiguo de Madrid, me será fácil aplicarla. ¡Gracias!}

8 de abril de $2015,3: 21$

\section{Figura 9: Comentário 1}

A outra amostra de coesão referencial presente em seu texto (Figura 9) relaciona-se ao uso do pronome oblíquo de terceira pessoa singular feminino: "la", anexado ao verbo em infinitivo (aplicar), conforme regra gramatical da língua espanhola. Ele remete a "la idea" diretamente, recuperando a expressão e, por extensão, indiretamente à atividade oferecida no post.

O segundo comentário da sequência (Figura 10), tal como o primeiro, apresenta uma posição elogiosa sobre a proposta, mas dirigida ao seu conteúdo e valor educativo para a comentadora, e não ao seu potencial uso didático-pedagógico. Todo o post é recuperado pelo sintagma nominal que abre a postagem ("Preciosa entrada rebosante de amor por Málaga"). Consideramos que se trata de uma estrutura de caráter metonímico, pois retoma o conteúdo da proposta de atividade por meio de um atributo positivo que a comentadora lhe confere, algo como uma declaração de amor à cidade. Nesse caso, estamos diante de outro exemplo de coesão referencial intertextual, como o citado no exemplo anterior.

\section{E Arancha dijo...}

Preciosa entrada rebosante de amor por Málaga. No sabes lo que he aprendido y eso que naci y me crié allí...;-D

8 de abril de $2015,12: 59$

\section{Figura 10: Comentário 2}

Ainda no comentário 2 (Figura 10), a elipse do pronome tu, em "No sabes", refere-se ao autor do blog. Indica uma referenciação exofórica de comunicação direta e dêitica. Como comentamos anteriormente, é um mecanismo comum à língua espanhola, na qual se omitem pronomes sujeito cujas pessoas já estão marcadas pelo verbo.

Em termos da coesão intratextual nesse comentário (Figura 10), "Allî" estabelece uma referenciação anafórica e dêitica ao referir-se à cidade de Málaga citada na frase anterior.

A figura 11 nos oferece uma oportunidade de observar a coesão estabelecida entre comentários. Como a interação é uma marca característica e esperada em pares post/comentário, não é raro encontrar recuperações de elementos de um comentário para outro. Nos casos de blogs, onde os blogueiros têm não só o papel de postar materiais, mas de interagir diretamente com seus leitores, respondendo seus comentários, tais enlaces intertextuais ficam mais claros. 


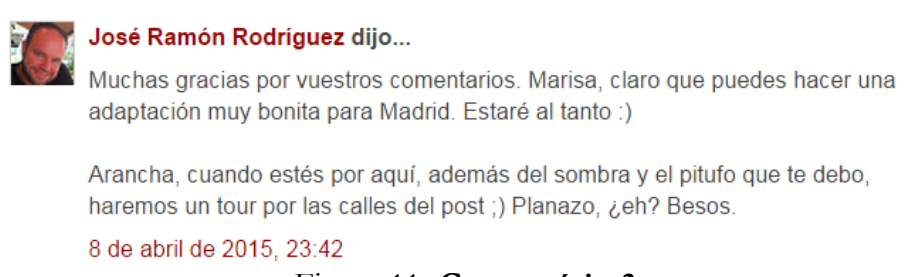

Figura 11: Comentário 3

Logo na primeira frase, José Ramón agradece as intervenções de ambas as leitoras. O uso do pronome "vuestros" (Figura 11), determinante de "comentarios", refere-se ao conteúdo dos dois primeiros textos (Figuras 9 e 10). Depois, em cada parágrafo, o autor volta-se às enunciadoras, utilizando seus nomes, remetendo diretamente aos sujeitos e não às suas falas (Figura 11). Tal remição dêitica se reforça pelo uso da segunda pessoa do singular (em verbos e pronome) para cada uma das professoras, em: "puedes" ("podes", em português), "estés" ("estejas"/"estiveres", em português), "te". Também se observa no uso da primeira pessoa do plural que, além de apontar para Arancha, inclui o próprio enunciador blogueiro: "haremos" ("faremos", em português).

Ainda na resposta de José Ramón (Figura 11), em “cuando estés por aquí,, o leitor precisa recuperar a informação do post que trata sobre Málaga e inferir que o blogueiro é dessa cidade da Espanha. Ou seja, estabelecer coesão com informações do post original. Isso é necessário para que possa construir a significação do advérbio dêitico "aquí", que se refere à Málaga.

Em 11 de abril, houve novo comentário ao post (Figura 12). O foco de seu autor recai no objetivo e conteúdo gramatical da proposta, ao contrário das comentadoras anteriores, que haviam enfatizado o caráter cultural. Outro aspecto, que se pode destacar em contraste com as mensagens anteriores, é que este enunciador não é espanhol, nem vive (ou escreve) na/da Espanha. O sintagma nominal que encerra o comentário e tem valor adverbial de lugar, estabelece uma dêixis com a localização desse sujeito: "desde Atenas", remetendo para fora do texto, no nível do contexto.

\section{spiros benetatos dijo... \\ Muy interesante la idea para practicar las oraciones relativas por las que no sienten gran simpatía los estudiantes. Muchas gracias por compartir y ser tan creative. Saludos cordials desde Atenas.}

11 de abril de 2015, 9:01

\section{Figura 12: Comentário 4}

Dentro do âmbito do cotexto, em “(...) por las que (...)" (Figura 12), o enunciador recupera a expressão "las oraciones relativas", que é o ponto gramatical a ser trabalhado na atividade proposta pelo post e não goza do apreço dos estudantes.

Os vários fragmentos e textos aqui discutidos nos permitiram, como pôde ser observado, refletir sobre construções coesivas referenciais concretizadas por meio de diferentes mecanismos, com o uso de distintos recursos da língua espanhola. Da mesma forma, pudemos ver que, em se tratando do meio virtual, em particular no par de gênero textual post/comentário, a coesão com frequência e de modo facilmente visualizado extrapola os limites tradicionais do texto, construindo-se intertextualmente. Refletimos, então, em nossa conclusão, sobre as implicações de tal construção em termos do processo de compreensão leitora.

\section{CONCLUSÃO: ALGUMAS REFLEXÕES SOBRE REFERENCIAÇÃO E LEITURA}

Este artigo se insere numa série de estudos que vêm sendo desenvolvidos no âmbito do 
Grupo de Pesquisa LabEV (Laboratório de Espanhol Virtual), sobre compreensão leitora e gêneros textuais com mediação pelas TICs. Oferece um recorte centrado na coesão referencial e, nesse sentido, tem como objetivo central analisar e discutir como se tecem as relações de coesão através da referenciação em textos virtuais, mais especificamente no par post/comentário de blog. Também propõe uma reflexão sobre suas implicações no processo leitor.

Para executar a tarefa, seguimos princípios teóricos apoiados na Linguística Textual, quando enfocamos o tema da referenciação, entendida como prática discursiva definida por estratégias interacionais e sociocognitivas. Nossa concepção de leitura, por sua vez, também leva em consideração tanto os aspectos cognitivos, quanto os sociais. E, no que se refere à prática leitora mediada por computadores, destacamos a importância de considerar o letramento enquanto continum, sempre passível de aperfeiçoamento pela vivência de práticas de leitura e escrita em sociedade.

Em virtude do nosso trabalho como docentes de espanhol como língua estrangeira, selecionamos para nossa amostra de análise um post a partir de um blog elaborado por um professor de espanhol. Este visa compartilhar atividades didáticas e tratar questões de ensino/aprendizagem do idioma com outros docentes. Assim, com base no post "Los gremios: las oraciones relativas en las calles de Málaga", pudemos observar como a referenciação ocorreu em cada gênero individualmente e também entre os dois. Ou seja, além de uma análise do processo de coesão intratextual, em cada gênero especificamente, buscamos também estabelecer como se deu a coesão intertextual entre o post e seus comentários e de ambos com textos externos ao suporte em questão.

No gênero post, a presença dos inúmeros links dispostos no decorrer do texto nos mostrou a importância de um objetivo de leitura claro. Isso para que o leitor pudesse acessá-los sem perder a coesão e construindo coerência a partir do material principal que estava sendo lido. Vários dos links exibidos no post selecionado não auxiliam diretamente na construção de sentido do texto principal. São, em geral, recursos que atuam ajudando o leitor a aumentar seu conhecimento enciclopédico, guardando sempre alguma relação (direta ou indireta) com o tema abordado. Há, então, a necessidade de uma maior atenção por parte do leitor para que a sua leitura não seja demasiadamente fragmentada e que o foco não seja perdido.

Um exemplo é o link que direciona o leitor para a página principal do jornal "Diario Sur". Há uma recuperação do periódico citado, mas o sujeito é direcionado para um ambiente virtual repleto de novas informações que poderão em nada acrescentar elementos à construção de sentidos do post que está sendo lido. Esse movimento pode acabar dispersando o leitor e, diante de tantas possibilidades de leitura, levá-lo, inclusive, a abandonar o post que estava lendo inicialmente.

No que tange a referenciação no gênero comentário, identificamos vínculos intertextuais (entre o comentário e o post principal) e também a coesão entre os comentários. A codependência própria do gênero, que requer sempre um texto prévio que o motive, explica a incidência dessa coesão intertextual. No entanto, ao contrário do que ocorreu no post, as referências a textos externos, por meio de hiperlinks, não foi frequente. Uma possível explicação pode ser atribuída ao perfil dos leitores, que buscam recursos para suas aulas, mais do que oportunidades de divulgar materiais próprios ou alheios.

No caso da coesão intratexto, a análise dos comentários nos permitiu identificar aspectos da referenciação bem característicos da língua espanhola, como a pronominal de objeto que não é tão presente na língua portuguesa e a elipse de sujeito.

Este artigo não pretende oferecer conclusões definitivas sobre a referenciação em língua espanhola no meio virtual. No entanto, consideramos que, tendo alcançado o objetivo de responder nossos questionamentos iniciais, abrimos espaço para a reflexão sobre o tema num contexto atual, cuja teoria se encontra ainda em construção. Considerando, contudo, o pequeno recorte escolhido, entendemos que as conclusões que apresentamos são parciais, não apontam para generalizações sobre o tema, mas fornecem elementos para futuras ampliações e 
contrapontos.

\section{REFERÊNCIAS}

CERUTTI-RIZZATTI, M. E. Letramento: uma discussão sobre implicações de fronteiras conceituais. Educação e Sociedade, Campinas, v. 33, n. 118, 2012, p. 291-305.

GASQUE, K. C. G. D. Arcabouço conceitual do letramento informacional. Ciência da Informação, Brasilia, v. 39, n. 3, 2010, p. 83-92.

JRAMONELE. Disponível em: < http://jramonele.blogspot.com.br/2015/04/los-gremios-lasoraciones-relativas-en.html>. Acesso em: 07 abr. 2015.

KOCH, I. G. V. A coesão textual. São Paulo: Contexto, 2009a. . Desvendando os segredos do texto. São Paulo: Cortez, 2009b. . O texto e a construção dos sentidos. São Paulo: Contexto, 2009c.

KOCH, I. G. V.; ELIAS, V. M. Ler e escrever: estratégias de produção textual. São Paulo: Contexto, 2009.

Ler e compreender: estratégias de produção textual. $3^{\text {a }}$. Ed. São Paulo: Contexto, 2007.

LIMA, Raquel Freitas de. O par post/comentário na rede social Facebook. 1. ed. Saarbrucken: Novas Edições Acadêmicas, 2015. v.1. 225p.

MARCUSCHI, Luiz Antônio. Linearização, cognição e referência: o desafio do hipertexto. Linguas e instrumentos linguísticos, Campinas, v.3, p.21-46, 1999. Disponível em: <web.uchile.cl>. Acesso em: 29 set. 2014.

Produção textual, análise de gêneros e compreensão. São Paulo: Parábola, 2008.

PERFETTI, C.A. LANDI, N. OAKHILL, J. A aquisição da habilidade de compreensão da leitura. IN: SNOWLING, M. J. HULME, C. (Orgs.) A ciência da leitura. Porto Alegre: Penso, 2013. p. 245-265.

PRENSKY, Marc. Digital Natives, digital immigrantes. On the Horizon, v. 9, n. 5, 2001.

SOARES, M. Novas práticas de leitura e escrita: letramento na cibercultura. Educação e Sociedade, Campinas, v. 23, n. 81, 2002, p. 143-160.

VERGNANO-JUNGER, Cristina. Elaboração de materiais para o ensino de espanhol como língua estrangeira com apoio da internet. In: Calidoscópio. [S.1.]: Unisinos, v. 8, n.1, 2010, p.24-37.

. Leitura e tecnologia da informação e comunicação: reflexões num âmbito universitário de espanhol como língua estrangeira. In: CARVALHO, T. L. de (Org.) Espanhol e ensino: relatos de pesquisas. Mossoró: UERN, 2012. p. 37-47.

Leitura na sociedade da informação e formação de professores: um olhar sociocognitivo. IN: Linguagem: Teoria, Análise e Aplicaşões, v. 8. [meio digital]. Rio de Janeiro: Programa de Pósgraduação em Letras/ UERJ, 2015. 
Aceito em 12/03/2019

Publicado em 02/04/2019 